\title{
Values in the Decision Making of CEOs in Public Colleges
}

\section{DAVID A. KEAST}

University of Alberta

\begin{abstract}
The effective administration of postsecondary education depends, to a significant degree, upon sound and systematic judgments by educational leaders in key administrative roles. The view taken in this paper is that "sound judgment" is comprised of rational decision processes combined with basic value choices. Yet, to date, one notices a conspicuous lack of research on decisions and values in higher education. The need for such research may be urgent, given our present climate of rapid change and economic restraint. This study examines the decision making and values of CEOs in public colleges. The paper provides an overview and comparison of types of decisions made, the processes used in decision making, and the value choices which influence those decisions.
\end{abstract}

This research was supported in part by a grant from the Social Sciences and Humanities Research Council of Canada. Thanks to Dr. J. Small, University of Alberta, and three anonymous reviewers for their valuable assistance in preparation of the final draft of this paper. 


\section{Résumé}

La qualité de l'administration dans le domaine de l'éducation postsecondaire dépend en bonne part de la qualité et de la logique des choix des dirigeants aux postes clef des institutions d'enseignement. On considère dans le présent article qu'un "bon choix" découle d'un processus de décision rationnel combiné à l'adoption de certaines valeurs de base. La recherche sur les décisions et les valeurs dans le domaine de l'éducation supérieure fait pourtant défaut. Or, dans le contexte actuel de changements rapides et de rigueur économique, c'est une recherche qu'il peut être urgent d'entreprendre. On se penche dans la présente étude sur les prises de décision et les valeurs adoptées par les présidents de collèges publics. L'article est une vue d'ensemble et une comparaison des types de décisions prises, des processus à l'œuvre dans la prise de décision et des valeurs adoptées qui influent sur ces décisions.

It will be worthwhile at the outset to extract one or two fundamental premises which form a basis for the design of the study which follows. The first can be expressed very simply: It is accepted as a basic premise that the administration of higher education is based in sound and systematic decision making. Having said this, one is faced with a number of difficult questions which will need to be addressed in order to become clear on the nature of this issue and its relevance for higher education. To state that administration of higher education is based in decision making tells us little about types of decisions made, about the process of decision making, or about what values underlie important administrative decisions. There is now acknowledgment in general administrative circles that in many important ways, administration is a value-based activity, and that there is a definite need for a more thorough and sensitive understanding of the role of values in administrative decisions. Thus, a second premise can be stated as follows: Important administrative decision making will be value-based. Simply put, where there are administrative decisions, there will be an appeal to certain values as a basis for decision making. Given our present social and economic climate, the need for understanding values is no less urgent in higher education. 
The contemporary research on decisions and values in administration has been affected by a number of important historical forces, not the least of which is the work of Barnard (1938) and Simon (1976). In The Functions of the Executive Barnard explicates what is, in essence, both a complex theory of decision and a theory of the role of morals in organizations. However, for Barnard, it is the moral element which is the most crucial. He describes a theory of morals for organizations in terms of the concept of morals and definitions of responsibility. Barnard says of morals:

Morals are personal forces or propensities of a general and stable character in individuals which tend to inhibit, control, or modify inconsistent immediate specific desires, impulses, or interests, and to intensify those which are consistent with such propensities .... When the tendency is strong and stable there exists a condition of responsibility. (p. 261)

Barnard further suggests that responsibility "is the power of a particular private code of morals to control the conduct of the individual in the presence of strong contrary desires or impulses" (p. 263). Responsibility thus refers to a consistency between one's moral code and one's action, a state where internal morality becomes effective in action. Conformity to moral codes due to sanctions or negative inducements is not, says Barnard, responsibility. It is, instead, a matter of right and wrong in the moral sense, a deep conviction, and not purely intellectual in character (pp. 265-266).

Barnard clearly regarded the moral element as fundamental to leadership and moral creativeness as key in understanding the dimensions of organizational morals. Moral creativeness involves creating moral codes for other organizational members. In its most common sense form, it is establishing morale, or, adjusting attitudes, values, and loyalties such that the result is subordination of individual interest in favor of the good of the organization. On moral creativeness and leadership Barnard suggests, "The creative function as whole is the essence of leadership" (p. 281). On the moral aspect of leadership he states, "the endurance of organization depends upon the quality of leadership; and that quality derives from the breadth of the morality upon which it rests" (p. 282). Barnard saw the creation of organizational morality as the spirit, the cohesive and integrating factor, which binds organizational members and overcomes the forces of individual interest. 
In Administrative Behavior, it is clear that Simon (1976) regarded decision making as central in the theory of administration. He states, "The task of 'deciding' pervades the entire administrative organization quite as much as does the task of 'doing' ... " (p. 1). It is also clear that he regarded value judgments as playing a significant role in administrative decisions. For example, he states:

"Decisions are something more than factual propositions ... they possess, in addition, an imperative quality - they select one future state of affairs in preference to another ... In short, they have an ethical as well as a factual content" (p. 46).

Although Simon acknowledged the importance of value judgments, he also adhered to a strict separation of fact and value, that is, a separation of "is" statements and "ought" statements. The following assertion captures Simon's view on the is/ought question: "The process of validating a factual proposition is quite distinct from the process of validating a value judgment. The former is validated by its agreement with the facts, the latter by human fiat" (p. 56). Simon, along with the logical positivists, ultimately assumed that there was no objective ground for understanding values.

One of Simon's main influences has been the advance of "rationalistic" models in the study of decision making. This approach emphasized the factual/scientific side of decision research and, although the role of values was acknowledged, there was a need to exempt values from analysis of the administrative decision making process. The impulse by researchers after Simon seemed to be to attempt to ignore or remove value considerations from decision research ( Beach, Mitchell \& Drake, 1978; Mintzberg, Raisinghani, \& Theoret, 1976; Struefert,1978; Suedfeld, 1978). Although Barnard (1938), even before Simon, had recognized and emphasized the importance of the moral element in an understanding of administration, there continued to be an emphasis on rationalistic approaches to and descriptions of decision processes in organizations.

More recent research in educational administration has revived interest in the important role of values in decision making. The existence of studies which examine decisions and values, although not highly prevalent, are now becoming more common. It would be accurate to suggest 
that these studies, mostly conducted in the $\mathrm{K}-12$ sector on the decisions and values of principals and superintendents, now form a distinct knowledge base upon which further systematic inquiry in this area can proceed (see, for example, Ashbaugh \& Kasten, 1984; Begley \& Leithwood, 1990; Campbell, 1992; Campbell-Evans, 1991; Leithwood \& Stager, 1989; Moorhead \& Nediger, 1991; Raun, 1992; and Walker, 1991). This research focus has, in turn, been inspired by the emergence of philosophical inquiry of the type exemplified by writers such as Hodgkinson (1978, $1983)$ and Greenfield $(1980,1982,1986)$. These writers have advocated a shift in viewpoint in administrative theory toward the importance of values, and have emphasized that administration is essentially a value-laden activity. Hodgkinson (1986) even advocates the dawn of a "new paradigm," indeed, a possible paradigm shift, with a view towards new directions in research, theory, and practice. These more recent trends have had a marked influence on the conduct of inquiry in educational administration and in the field of education in general.

The importance of understanding the nature of administrative decision making cannot be overstated, especially given the fact that this decision making takes place in, and is partially shaped by, a social and organizational context. The complexity and significance of administrative decisions lies simply in the fact that such judgment occurs in contexts where the most important judgments directly effect the lives of significant numbers of others who live and work in those same contexts. If it is true that such judgments are value-laden, then the importance of studying and understanding the nature of decisions and the values which underlie decisions is undeniable. And this surely applies in almost any organizational and administrative setting. It is, without doubt, particularly relevant for higher education.

What is noteworthy, however, is that although the study of decisions and values is now becoming established in general administrative circles, in higher education there is a conspicuous absence of such research activities. A preliminary review of library holdings at the University of Alberta from 1984 to the present shows little in the way of theory or research related to ethics or values and decision making in higher education. Searches of the ERIC database also revealed only small numbers of 
studies in this area. The literature which does exist can be divided into roughly three categories: leadership theory and research, decision making, and ethics or values. Leadership theories and leadership studies are by far the most plentiful, but even here, studies in higher education depend for a foundation on theory and research from other fields. Bensimon, Neumann, and Birnbaum (1989) suggest that "leadership has been studied in business organizations, the military, and governmental agencies, but little attention has been given to leadership in higher education ..." (p. 7). Examples of studies in higher education tend to focus on the definitions and responsibilities of leadership and to advocate an approach to governance based on a knowledge and application of various theories of leadership and conceptual frameworks for understanding organizational functioning (see for example Bensimon, Neumann, \& Birnbaum, 1989; Birnbaum, 1986, 1987, 1988; and Vaughan, 1989). In a recent work, Birnbaum (1992) provides a comprehensive view of the nature of leadership and the sources of effective leadership, including relations which promote institutional renewal, and makes recommendations on how to improve academic leadership. In this type of research, emphasis on decision making tends to be placed on organizational decision processes, with little or no systematic analysis of the decision making of leaders or relations between decisions and values.

Aside from the general context of leadership theory and research, literature pertaining specifically to leadership decision making appears sparse. One example is Plante's (1987) work which provides a number of case studies with suggested solutions and clearly emphasizes values as an important basis for decision making. Prior to 1984, Dressel's (1981) work is notable for addressing both ethics or values and decision making in leadership. However, in both these works, discussions are either too brief or too generalized and applicable in a variety of contexts, and therefore do not provide enough systematic theory-building which could form a foundation for focused conceptual frameworks and empirical research in the area. Given more contemporary work on decisions and values (see Ashbaugh \& Kasten, 1984; Campbell-Evans, 1988; Hodgkinson, 1983; McPhail-Wilcox \& Bryant, 1988; and Leithwood \& Stager, 1989, as examples) Dressel's conception of decision making and ethics appears somewhat dated. 
Much of the work on ethics in higher education focuses quite extensively on the professional roles of leaders and codes of professional conduct. Wilcox and Ebbs (1992) discuss the importance of ethics for higher education, examine theories of leadership and organizational conceptual frames, and address the ethical aspects of professional roles of leaders and standards of professional conduct. Thompson's (1991) edited work contains theoretical and philosophical papers on topics ranging from values in institutes of higher education to the moral responsibilities of universities in society. Robinson and Moulton (1985) provide a brief discussion of the major ethical theories and explore issues such as the university and its relation to society, ethics in hiring and evaluation, and ethics in research and teaching. May's (1990) edited work contains accounts of the relationship and importance of ethics and organizational culture, ethics in activities such as planning, recruitment, selection, athletics, and evaluation, and a discussion of a variety of other moral issues.

Inquiry directed specifically to the question of values in higher education is scarce. Burton Clark $(1982,1983)$ provides one example (perhaps the only one) of a value classification scheme relevant for higher education. Clark posited four value categories including social justice values, competence or quality oriented values, values of liberty or freedom, and values of loyalty. These four value sets are discussed in relation to different aspects of governance and organizational functioning. Dennison's (forthcoming) work, which analyzes and discusses Clark's typology, is the only known work of this kind in Canada which addresses the question of values in the community college setting.

Literature which discusses the decision making of leaders in higher education in conjunction with the value bases of such decisions is almost non-existent. The work of Vaughan (1992) and Smith $(1984,1985)$ is notable as being among the only examples found. Vaughan's edited work specifically addresses decision making and ethics in the community college setting. The problem here, as is the case with much of the literature previously discussed on ethics in higher education, is that contributions are made by a variety of practitioners and are primarily descriptions based on personal experiences with little grounding in systematic theory or empirical research and, therefore, with few unifying influences. Aside 
from this, Smith recounts a study of values and institutional decision making in eight academic organizations conducted under the auspices of the Society for Values in Higher Education. Unfortunately, apart from Smith's contribution, little writing exists documenting study findings.

Overall, a variety of approaches and topics seems to be present, without the benefit of clearly defined theoretical underpinnings, common conceptual frameworks, or a central focus. As will be seen in a later section of this discussion, the types of critical decisions which respondents in this study faced were not essentially different in kind from those faced by administrators in other educational sectors in which similar research is being conducted. If what was said earlier concerning the importance of decision making and values is true for administration in general, it will be no less true for higher education. Allowing for some variation in the type of stakeholders and scope of variables found in higher education as compared with other sectors, crucial decisions in higher education are, nonetheless, educational decisions, and therefore fraught with complex value choices. What may be lacking in analyses of policy, planning, implementation, and appraisal in higher education is an awareness of underlying values which inevitably form a foundation for these activities. An emphasis on this apparently ignored dimension of administration in postsecondary education may allow for a broader view of organizational functioning based on a deeper understanding of administrative behavior. Government policies and socio-economic constraints may indeed impinge in numerous ways on the functioning of higher education institutions but it is ultimately the judgment that comes from within institutions themselves that sets the course for future development, and it is the values which underpin those judgments which are crucial for understanding leadership in higher education. What may be needed is not only a focus on external factors which affect institutional functioning but also examination of the decision processes which drive organizational functioning.

In the most general sense, the main purpose of this study was to examine relations between administrative decision making and the values which influenced those decisions. The design of the study, data collection, analysis, and interpretation were guided by four main research questions 
relating to (a) the types of decisions made by respondents, (b) the possibility of patterns in decisions and values as they relate to decision types, (c) the nature of the decision process used by respondents, and (d) the extent of similarity in values among respondents. In addition, one important underlying intention was to bring the problem of decisions and values to a sector of education - in this case, public colleges - in which little or no research of this kind now exists. The study afforded an opportunity to examine various dimensions of critical decision cases and to relate these to the values which underlie decision making processes.

\section{Framework}

The conceptual framework employed for this study consists of three components: a decision classification scheme or typology, a decision process model, and the identification of values. Research on school principals conducted by Ashbaugh and Kasten (1984) provided the initial inspiration for the decision typology, however, the theoretical framework originates in the writings of Kimbrough and Nunnery $(1983,1988)$. These authors described different types of administrative decisions according to administrative task. This, in turn, amounts to different aspects of organizational operation over which an administrator is likely to have decision making responsibility. Kimbrough and Nunnery proposed eight different categories as follows:

1. Organizational structure; decisions which involve re-structuring in order to realize mission statements or objectives, or address communication, planning, and other operational or strategic needs.

2. Curriculum and instruction; decisions involving the organization and management of teaching and learning processes, including program evaluation.

3. Finance; decisions involving choices about scarce resources.

4. Management of support services; decisions regarding all support services including transportation, food services, equipment purchases, and so on, and supervision of noninstructional personnel. 
5. Staff personnel administration; decisions based on policies covering instructional personnel including recruitment, selection, promotion, dismissal, evaluation, and professional development.

6. Student personnel decisions; all decisions directly related to students but not related to curriculum and instruction.

7. Buildings and facilities; decisions concerning capital development.

8. School-community relations; decisions concerning relations with various external community stakeholders.

Two points are worth mention regarding the decision typology. First, it was not expected that cases received would fall clearly and exclusively within one type or another. There were in fact cases in which overlap existed where, for example, a case could be regarded as organizational structure and finance simultaneously. Thus, the criterion which stood out as primary or, simply, what the case was essentially about, served as a basis for classification. The classification of decision cases by the researcher was confirmed by respondents in all instances.

Second, the classification scheme as used by Ashbaugh and Kasten (1984) was applied in the principalship setting, while in the present study, it was applied in the postsecondary setting. It was expected that minor modifications and refinements would be necessary. In total, 24 cases were obtained from respondents which fell into seven of the eight categories proposed by Kimbrough and Nunnery (1988). No student personnel cases were received from the respondent group. In addition, minor name changes were made in one or two categories, as well as further divisions into sub-categories. Table 1 displays all cases obtained by type and sub-type.

The second component of the conceptual framework used for this study consists of a rational model of decision making. It is undeniable that this model has been strongly influenced by the body of research which precedes it. From the work of Simon (1976) onwards, decision studies have stressed a rational view of decision making, one where the decision process is explained by being broken down into identifiable steps or stages. A few examples will illustrate. Mintzberg, Raisinghani, and Theoret (1976) in studying organizational decision processes 
Table 1

\section{Breakdown of Number of Cases by Type}

Type

Number of Cases

Personnel

10

(Staff Personnel 7)

(Adm. Personnel 3)

Organizational Redevelopment

6

(Planning

4)

(Restructuring

2)

Buildings \& Facilities

Finance

C. \& I.

Board Relations

Support Services Adm.

described three basic decision stages-identification, development, and selection-in which could be found further stages or sub-routines. The result of this analysis was a general model which formed the basis for seven different variations of decision making. Similarly, MacPhailWilcox and Bryant (1988) in a review of literature on decision making, suggest that " at least three major stages appear with some consistency in the literature" (p. 8). The stages identified by these authors are (a) perception and information gathering, (b) information manipulation and processing, and (c) choice strategies.

There are, in addition, a number of assumptions concerning the validity of rational decision models and their prevalence in practice which are worth mentioning. First, although we can never be certain because we do not, per se, have direct knowledge of the mental operations of decision makers, we 
can infer on the basis of experience, observations of others, and common sense, that most important administrative decisions are rational in nature. In other words, when administrators are faced with complex dilemmas they are most likely to develop reasoned strategies and solutions to those dilemmas. Another way of stating this is to ask whether administrators can afford not to make adequately reasoned decisions on important issues. This inference is borne out not only in previous research but also in analysis of data in the pilot study conducted for this research. Decision makers tended not to rely on alternate modes of decision making when asked about such things as hunches or gut feelings. Although these were present, administrators tended to distance themselves from these feelings and strive for an objective view of the given situation.

Second, justification of the use of decision models in administration other than those which are rational seems problematic. Interest in purely distinct alternatives to a rational view of decision making is, as of yet, scarce, if not non-existent in administrative research. An additional problem arises, of course, in not only the testing of such a model but even in its description or explication. In other words, could there be such things as models, necessarily logically constructed, which are non-rational or a-rational? How would such models be described and tested or, on what grounds could we discern that such a model, if constructed, had any degree of validity? Rather, it is suggested here that an effective way to identify values is by looking through the rational decision process into the value dimension. Once this is accomplished, we shall discover that values are not entities distinct from decision making but simply another important and fundamental aspect of decision process itself. To say that a judgment is rational is simply to suggest that a choice has been made between alternatives, or between consequences, or goals, or based on non-consequentialist principles or convictions. This choice, in turn, supposes that basic reasons can be given for choosing $\mathrm{A}$ over $\mathrm{B}$, and the giving of reasons constitutes something akin to implicit or explicit value statements; in other words, such statements constitute an answer to the question "Why A over B?"

A diagrammatic representation of a model for decision process is displayed in Figure 1. This model was neither totally preconceived nor 
totally emergent. Although the model provided a guide for interviews and reflects the general framework for analysis of decision process, modifications and refinements were made as a result of sub-categories emerging from analysis of data.

The decision process, as depicted, is composed of three general stages and a number of major components or categories. First, prerequisite to most administrative decisions, rational or not, is identification and definition of a problem or dilemma - in effect, a conflict - between real states of affairs and those that are ultimately desired. The representation provided in Figure 1 depicts the problem development stage as being comprised of problem definition, perceptions of others, identifying stakeholders, information gathering, and the effects of policy and procedures and historical factors. This stage corresponds to much research and was roughly confirmed in the pilot study.

The next stage, solution development, consists of a number of categories including alternatives considered, non-rational factors involved in decisions, constraints identified, strategies used, and predicted outcomes of decisions. Finally, the implementation stage represents the point at which a choice is made to commit to action. The decision is finally borne out in action through implementation. Expected and unexpected outcomes emerge in response to implementation and actual constraints impinge at all points in the decision process. The nature of the decision process model depicted in Figure 1 will be discussed again in more detail in a later section.

The third important aspect of the conceptual framework is the identification of values. A number of sources were used in designing the conceptual framework and in projecting an idea of what one might possibly find upon conducting research into values. For example, both the theoretical and empirical work of Rokeach (1973) on values and value systems has been extensive. He defined a value as "an enduring belief that a specific mode of conduct or end-state of existence is personally or socially preferable to an opposite or converse mode of conduct or endstate of existence" (p. 5). Rokeach distinguished two kinds of values, each, in turn, divided into two types. Terminal values are those beliefs which concern end-states of existence, and they may either be of the 


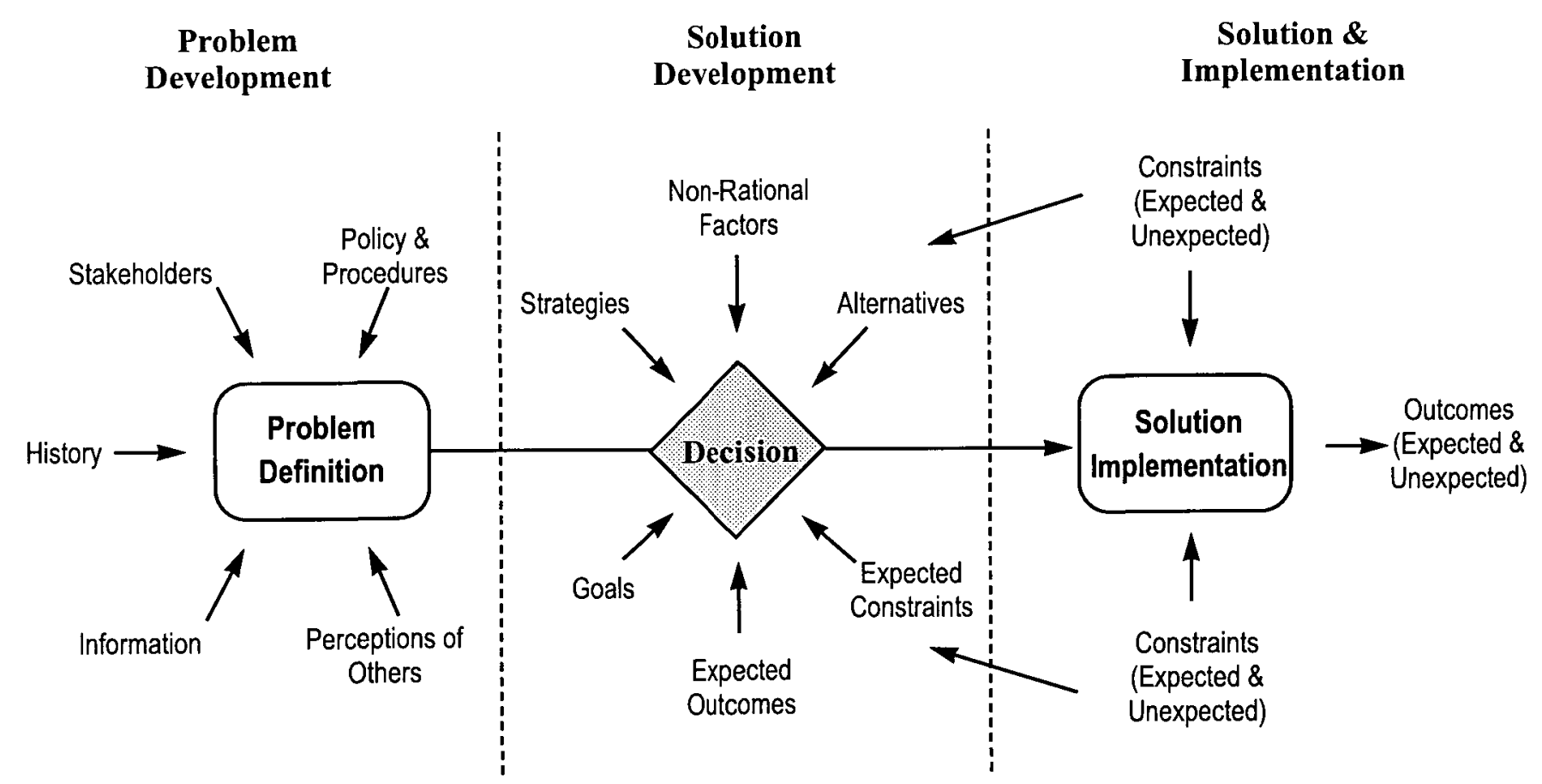


self-centered or society-centered type. One may be concerned with peace of mind as a personal end-state, or with world peace or brotherhood as an interpersonal end-state. Instrumental values, those concerning modes of conduct rather than end-states, may be moral or competence oriented. Thus, being honest or responsible is moral, while acting intelligently or imaginatively is concerned with competence values. Rokeach also suggested that the actual number of values human beings hold is assumed to be relatively small. He estimated that the total number of terminal values that a grown person possesses is about "a dozen and a half," and the total number of instrumental values is somewhat larger, "perhaps five or six dozen" (p. 11). Rokeach believed that human values are finite in number and therefore measurable.

Beck (cited in Campbell-Evans, 1988) seemed to believe (along with others such as Rokeach, 1973) that values were based in human need and since individuals and groups have similar basic needs and are faced with similar types of problems, a fairly common set of universal values exists. He identified five sets or types of values: (a) basic human values including, for example, survival, happiness, self-respect, knowledge, and freedom; (b) moral values including such concepts as responsibility, courage, and self-control; (c) social and political values including justice, due process, and participation; (d) intermediate-range values including food, shelter, entertainment, and fitness; and (e) specific values including such things as a car, a good television, a particular friendship, or a particular sport. Beck further suggested that the categorization of values should be regarded as fluid and open. Values should not be viewed in isolation but rather as part of an interacting system.

Two problems are apparent in attempts to understand values in relation to value classification schemes. First, definitions of values, different value types, and associated concepts such as ethics and morals, vary widely among researchers. In the present study, statements coded as values were deemed to have moral or ethical import beyond individualistic levels. No interest was taken in statements which may have reflected mere personal preference. Values were regarded as expressions of moral principles in relation to complex decisions and as indications of the rightness or wrongness of action ensuing from such decisions $A$ value 
judgment or choice, therefore, may be taken to have moral content, and to be roughly synonymous with an ethical or moral judgment or choice.

A second problem relates to the method of classifying values and to the validity of value categorization schemes in research. In the present study, theories of value and value systems, although informative, served merely as a rough background for the coding of values and in a few cases, the transposition of value statements into more generalized concepts. Thus, value schemes served their primary purpose as reference lists in the reporting of data. One main reason for this approach is that there appear to be discrepancies in the classification of values by different researchers. For example, values reflected in statements like "What's good for kids" were classified as a type of organizational value by Ashbaugh and Kasten (1984). Similar findings were classified as transcendent values by Begley (1988). The statement "I have a strong work ethic" was regarded as a transcendent value by Ashbaugh and Kasten; however, it could be easily argued within an educational setting that such statements represent organizational values. The statement "Violation of the rights of others cannot be permitted" was again classified as transcendent by Ashbaugh and Kasten, yet, the classification of such statements as reflecting political values does not seem inappropriate. These types of discrepancies raise a larger question concerning the validity of classification systems such as those mentioned above, and their use in further research. That is, there seems to be very little logical grounding for arbitrary classifications where specific values are placed in one category rather than another. Indeed, we become plagued by the problem of providing good reasons for classifying a concept such as truth as a basic human value, or a moral value, as opposed to a social or political value.

Therefore, one important respect in which this study differs from previous research is that although other value classifications were used as a background, no preconceived value categorization system was imposed a priori in the analysis of data. Aside from the obvious educational context in which the study was placed, any classification of values identified and coded in data exists only in relation to the decision typology. In this way, the numerous problems associated with preconceived classifications of values such as moral, political, basic human, terminal, or instru- 
mental, can be avoided. Given that value judgments do not exist in a vacuum but are, rather, context dependent, it is expected that the identification of values in relation to types of decisions made by administrators will enhance the transfer of knowledge.

\section{Method}

\section{Design and Data Collection}

A qualitative, two-phase design was adopted for this project with emphasis on multiple case study analysis and comparison. The respondent group consisted of presidents in ten public colleges in the province of Alberta. Two rounds of interviews were conducted with respondents which resulted in two phases of data collection and analysis.

All respondents were first sent an introductory letter explaining the required steps of data collection and requesting that they recall two to three critical decision incidents which they had faced in their roles as presidents. Respondents were asked to describe cases which they regarded as difficult in that problems and solutions to problems were not clear-cut, important to the institution in terms of teaching and learning, and within their decision making jurisdiction in that decisions were made directly by them or were ones for which they took direct responsibility. These decision incidents were then returned for analysis and classification, and were used to set the stage for Phase I interviews. Tape recorded, semi-structured interviews were conducted with each respondent based on the decision cases which they had submitted. Full transcripts of interviews were prepared and subsequently coded and content analyzed. Analysis of Phase I interviews focused first on the decision processes involved in resolving the cases, and second, upon values implicit in decision making.

In Phase II, a simulation approach was used. A sub-sample of four respondents was selected from the original group and asked to react to two representative cases chosen from those initially received. It was important in this selection that participants not view their own decision cases, thus, respondents were chosen who were not original authors of the cases used in Phase II. The choice of cases for Phase II was based on 
the types of decision incidents received, and on the clarity and amount of revision or alteration necessary in order to maintain confidentiality, and at the same time preserve the complexity of the case. Again, interviews in this phase were analyzed for decision process and values. The design allowed for analyses and comparisons both within and between phases.

\section{Data Analysis}

The data collected in this study were subjected to a number of different forms of analysis. Specific data on characteristics of the cases themselves, or case attribute data, were collected prior to each Phase I interview. The purpose of these data were to enhance the overall picture of the types of cases obtained for the study. Similar data were collected again in Phase II interviews for purposes of later comparison across phases.

Analysis of decision process and values in the first phase of interviews included three passes on the data to ensure consistency in coding. Data summary sheets were also used allowing for detailed analysis of both the frequency of occurrence of responses and the content of responses. In addition, case summaries were written by the researcher on each case highlighting only the most salient points. The case summaries were used to enrich description and corroborate previous findings.

Values analysis in Phase I followed a similar process to identification of other categories. Aside from some coded responses being subsumed under others, and the identification of synonymous codings, values were subjected to no further interpretation. Profiles of case types were then created based on cumulative analyses for Phase I. Profiles consisted of a summary of findings on type-specific patterns in decision process and in values, by case type.

In analysis of data from a second round of interviews, or, Phase II interviews, consistency with methods established in Phase I was regarded as important. Therefore, two passes on these data were included. The coding scheme developed in Phase I was found to be generally applicable in Phase II. Only two new sub-categories were adopted. Again, case summaries were prepared based on each case interview. Similarly, values identified in the first phase were used as a "backdrop" for values analysis in Phase II. In all, only one additional value - academic freedom - was 
identified which did not occur in Phase I. Profiles were created which discussed and summarized decision process and values findings in each of the cases used in Phase II.

A final approach consisted of analysis of data across both phases. Three components or sets of data were compared: (a) case attribute data from both phases, (b) findings for the decision process in both phases, and (c) findings for values in both phases. In addition, three possibilities for type-specific patterns were considered: (a) patterns identified only in Phase I, (b) patterns identified only in Phase II, and (c) patterns common to both phases. Profiles of case types were used to enhance the exploration of type-specific patterns across both phases of data.

\section{Summary of Findings}

Of the three main sets of data collected in this study, results from analysis of pre-interview data on the characteristics of cases are inconclusive and therefore will not be reported in this discussion. Data from interviews in Phase I and Phase II were analyzed for the decision process and values. The main findings from analysis of each of these data sets will be discussed in turn. Given restrictions of time, it was not possible to conduct interviews on the one support services administration case received; therefore, analysis and explanation of decision process and values is based on a total of the 23 remaining cases.

\section{The Decision Process}

Of all major constructs investigated in this study the decision process, by far, proved to be the most complex and at the same time, the most elusive. In all, 11 major categories were identified and coded in Phase I. These categories, in turn, dissected into a number of sub-categories. Because of the simulation-like nature of Phase II, certain questions and therefore certain categories could not be further investigated. In total, in Phase II, data were collected in eight major categories. Unexpected outcomes and constraints were not identified in Phase II data. Thus, analysis and comparison of the decision process in two phases was limited to categories and case types common to both phases. In addition, brief 
mention will be made of other salient findings in categories and case types in Phase I. The main interest in this discussion focuses on patterns which are most evident within specific types and, particularly, patterns which are consistent across phases.

A number of potential type-specific patterns were identified in either Phase I or Phase II in organizational redevelopment cases. In all, however, only three patterns stand out as recurring across phases in this case type. In both phases respondents identified a lack of institutional mission or vision. This was identified as a dilemma in Phase I and as a nonrational factor in Phase II, and was further supported through analysis of case summaries in both phases. In Phase II, respondents also identified the importance of the performance and support of senior administrators in the change process. This finding was reinforced in a number of categories in Phase I, including perceptions of others, strategies, and particularly in outcomes and constraints, and further reinforced through review of case summaries in Phase I. Finally, respondents did not often maintain and work within existing conditions or use existing structures or models as an alternative course of action. Rather, they opted for moving forward on large scale change initiatives. No claim is being made for the exclusiveness of these patterns to organizational redevelopment cases. However, within the context of this study, these three recurring patterns emerge as the strongest candidates for patterns which appear to be highly characteristic of this case type.

Similar to findings for organizational redevelopment cases, findings for personnel cases showed a number of potential type-specific patterns in either Phase I or Phase II data. Fewer patterns, however, seem to exist across phases. In personnel cases four such patterns were identified. First, the theme of ambiguity or conflict in information and evidence from evaluations, the legitimacy of such evaluations, and adherence to due process, was reinforced in categories in both Phases I and II and further reinforced though analysis of case summaries in both phases. This problem was clearly endemic to this case type across phases. Second, the strategy of consultation, defined here as a specific act in response to recognition of a problem, was clearly dominant in both phases of data. It appears as though respondents, first and foremost, seek out relevant others to consult 
when confronted with a personnel dilemma. Third, solutions to the personnel cases collected here seemed to be oriented toward the achievement of shorter term goals. This appears consistent with the quite specific nature and time frame for such cases, particularly for those involving dismissal. Solutions exhibited what might be called a "practical logic" of personnel cases which often consisted of negotiating a compromise and quiet removal from the institution. Fourth, in spite of the fact that reactions were expected from a number of constituents in and out of the organization, in both phases, concern was expressed over the expected reaction of the faculty member impacted by the decision.

A number of recurrences were noted in all three buildings and facilities cases obtained, although description for this case type is limited to Phase I data analysis. Overall, three patterns were identified as highly consistent. First, in all three cases an already existing document or plan laid the groundwork for the initiative. Thus, the identified need had, at some point in the past, been discussed before. However, in all cases the existing document served only as a conceptual springboard from which a new and more relevant initiative was adapted. Second, at some point in each case an individual, strategically chosen or placed, played a crucial role in liaison with key external stakeholders such as government departments or private corporations. This individual was a member or chair of a special committee or, in one case, someone internal to the college organization. Third, the success of each case depended in a very essential way on satisfying the mutual interests of major stakeholders involved. The addressing of this political and economic reality seemed to be a necessary condition for the success of each case.

Very little in the way of consistent evidence exists for patterns in the unexpected outcomes and constraints categories in Phase I. The most consistent findings were in buildings and facilities cases. Here, all references to unexpected outcomes referred to various external communities or stakeholders involved. Most comments were negative in nature referring to forms of maneuvering and resistance by various groups in the realization of the initiative. Participant responses on expected constraints to decision making showed some identified constraints occurring slightly more in some types than others. The board was named as a constraint in 
three out of ten personnel cases. In organizational redevelopment cases, resistance to change and the resistance of senior administrators seemed to dominate. In buildings and facilities cases, again, the actions of various external communities were identified as a constraint.

Findings for unexpected constraints are sketchy. In a total of eight cases in Phase I, the accuracy of or lack of information or knowledge seemed to dominate in participant responses. Negative unexpected reactions from external communities were noted exclusively in all three buildings and facilities cases.

What is perhaps most interesting is the identification of constraints across all cases. Overall, time was the most mentioned constraint in all cases. Other constraints, expected and unexpected, occurring across cases were resistance to change from the internal college community, the board, and the resistance of senior administrators.

\section{Values}

The identification of values in Phase I data consisted of coding and classifying values in 23 cases. In all, 29 values were identified in Phase I. In Phase II, interviews with all four respondents were again coded for value choices. In this phase, 17 values were identified in all.

Two levels of analysis will need to be discussed. First, general frequencies of occurring values across all cases were examined and compared in both phases. Second, and more importantly, recurring values within the two major case types were examined across both phases of data. Finally, some mention will be made of how value choices in Phase II cases compare with value choices made by original authors of those cases in Phase I.

Table 2 shows findings for general frequencies of values in both phases, rank-ordered from highest to lowest occurrence in cases. In Phase I, the 10 most frequently occurring values are displayed. For Phase II, the list shown represents the nine highest occurring values. In Phase I, fairness ranks highest, while in Phase II, trust ranks highest with fairness second highest. In Phase I, four values - faculty interests, empowerment, collegiality, and ownership - occur within the top ten which do not occur in the nine values displayed in Phase II. However, four out of the 
Table 2

Occurences of Values in Phase I and Phase II Rank-Ordered from Highest to Lowest Occurrence in Cases

\begin{tabular}{lclc}
\hline \multicolumn{2}{c}{ Phase I } & \multicolumn{2}{c}{ Phase II } \\
\hline Values & $\begin{array}{c}\text { Total Cases } \\
(\mathrm{N}=23)\end{array}$ & Values & $\begin{array}{c}\text { Total Case } \\
\text { Interviews }(\mathrm{N}=8)\end{array}$ \\
\hline Fairness & 9 & Trust & 6 \\
Shared Decision Making & 9 & Fairness & 4 \\
Institutional Interests & 8 & Student Interests & 4 \\
Student Interests & 6 & Shared Decision Making & 3 \\
Faculty Interests & 6 & Shared Vision & 2 \\
Shared Vision & 4 & Institutional Interests & 2 \\
Collegiality & 3 & Quality of Education & 2 \\
Ownership & 3 & Respect for Persons & 2 \\
Quality of Education & 3 & Consensus & 1 \\
Empowerment & 1 & & \\
& & & \\
\hline
\end{tabular}

five highest occurring values in Phase II are also shown in Phase I. In all, six out of the nine occurring values in Phase II are among those listed in Phase I. Of the three remaining values, trust also occurred in three cases in Phase I but is not shown in Table 2.

Table 3 shows findings for recurring values by case type in Phase I and by case interview in Phase II. As can be noted from these findings, shared decision making ranked highest for organizational redevelopment cases in Phase I while trust ranked highest in Phase II, with shared decision making second highest. Trust did not occur at all in organizational redevelopment cases in Phase I. Of the three recurring values in organizational redevelopment case interviews in Phase II, two values - shared decision making and shared vision - occurred exclusively in these interviews and also recurred 
Table 3

Recurring Values by Type in Phase I and Case Interview in Phase II

Phase I

\begin{tabular}{lccc}
\hline \multicolumn{2}{c}{ Org Re-D Cases $(\mathrm{n}=6)$} & \multicolumn{2}{c}{ Org Re-D Case Interviews $(\mathrm{n}=4)$} \\
\hline Values & No. of Cases & Values & $\begin{array}{c}\text { No. of Case } \\
\text { Interviews }\end{array}$ \\
\hline
\end{tabular}

Phase II

Trust 4

Shared Decision Making 3

Shared Vision

2

2

Pers Cases $(n=10)$

Pers Case Interviews $(n=4)$

$\begin{array}{llll}\text { Fairness } & 7 & \text { Fairness } & 4 \\ \text { Institutional Interests } & 5 & \text { Student Interests } & 3 \\ \text { Faculty Interests } & 3 & \text { Institutional Interests } & 2 \\ \text { Shared Decision Making } & 2 & \text { Quality of Education } & 2 \\ \text { Student Interests } & 2 & \text { Repsect for Persons } & 2 \\ --- & & \text { Trust } & 2\end{array}$

Note: $\operatorname{Org} \operatorname{Re}-\mathrm{D}=$ organizational redevelopment Pers $=$ personnel 
in Phase I organizational redevelopment cases. In personnel case interviews in Phase II, fairness ranked highest in recurrence and this was found to be consistent with Phase I personnel cases. In personnel case interviews in Phase II, the top three recurring values also ranked highly in personnel cases in Phase I and two out of those three, including fairness, occurred exclusively in Phase II personnel interviews. The remaining three values - quality of education, respect for persons, and trust did not recur significantly in Phase I within the personnel type.

Finally, comparison of value responses in Phase II interviews with value choices by original authors of the two cases in Phase I seems to show the least extent of consistency. In Phase I, from a total of five values identified in interviews with the original author of the organizational redevelopment case, only two values - shared vision and student interests - occurred among all values coded in Phase II organizational redevelopment case interviews. Shared vision recurred in two out of four of these interviews in Phase II. In transcripts of interviews by the original author of the personnel case, four values were identified. Of those four, two values also occurred in Phase II personnel interviews. The two values in common, however, were fairness, the highest recurring value for personnel cases in both phases, and trust, which recurred in two out of four personnel case interviews in Phase II.

\section{Discussion}

Four concerns will be addressed in this section which correspond roughly to the major research questions stated earlier relating to (a) the types of decisions made and the decision typology, (b) the possibility of patterns in decisions and values as they relate to decision types, (c) the nature of the decision making process, and (d) the extent of similarity in value judgments among respondents.

The main purpose of the decision typology was to provide a contextual classification scheme for better understanding the decision process and values. The approach used was to allow values to be classified relative to the types of decisions in which they were immersed and from which they originated. Aside from minor name changes, the typology 
was deemed to be generally applicable for respondents and cases received in this study. However, some qualifications are necessary.

In the study of school principals by Ashbaugh and Kasten (1984), the study from which the typology used here was adapted, personnel decisions emerged as the most frequently occurring. In that study, 51\% of decisions were of the staff personnel type. Likewise, in the present study, personnel decisions outnumbered all other types. Ten out of 24 cases, or almost $42 \%$ of cases received were personnel. Seven out of ten of these cases were staff personnel, and the majority of these were dismissals. Ashbaugh and Kasten found student personnel decisions to be the second most frequently occurring. Thirty-one percent of cases classified were student personnel, followed by school-community relations cases, at $16 \%$. In the present study, organizational redevelopment cases were the second most frequently occurring. Six out of 24 cases, or $25 \%$ were of the organizational redevelopment type.

A number of factors may account for differences in the frequency of types of cases collected and categorized, the most likely of which is a difference in the professional ranks of respondent groups used in the studies. Ashbaugh and Kasten (1984) examined the decision making and values of school principals, whereas the respondent group in the present study consisted of CEOs of public colleges. Aside from the occurrence of staff personnel decisions, these two professional roles seem to differ somewhat with respect to the types of decisions which respondents faced in their work. It should be noted that no claim is being made here for generalizability to other systems or sectors of education. More research is needed to determine the applicability of this model beyond the respondent group and cases used in this study.

A second concern was the identification of patterns in decision process which were highly characteristic of or specific to decision types. As was noted in the previous section, seven type-specific patterns were discerned in two case types across both phases of data. Personnel cases revealed the problem of legitimacy or accuracy of evidence in evaluations and adherence to due process; consultation as a dominant strategy; compromise and neutralization as recurring short-term goals; and concern over reaction of the impacted person as an expected outcome. 
Organizational redevelopment cases revealed a persistent lack of shared vision as a main dilemma; a problem of support and resistance from senior administration in a number of categories; and all respondents opting for large-scale change initiatives. In addition, three buildings and facilities cases clearly revealed three factors important in the success of each case, although since no buildings and facilities cases were used in Phase II, these findings are limited to Phase I analysis.

Part of the overall conceptual framework included the adaptation of a rational decision model. The general approach to investigating decision making, including the development of interview guides was, to some extent, dependent on this model. A number of findings as a result of data analysis here can be compared to other relevant research on decision making. For example, in a study of organizational decision making processes, Nutt (1984) found a relatively high percentage of the use of either the ideas of others and past experience and background, or already existing models and already tried methods, as solutions to problems. This was found in $71 \%$ of decision cases in Nutt's study. Findings in this study do not reflect similar conclusions. In many cases in which history, background experience, or existing documents, models, or structures were available, they were not used. Instead, respondents tended to opt for large scale and somewhat risky change initiatives. This inconsistency in findings may reflect a lack of distinction in defining a problem as opposed to defining a solution. In this study, although history and existing structures played a role in definition, this did not seem to be the case in solutions.

Furthermore, normative views of decision making tend to emphasize analysis and consideration of possible alternatives, and the outcomes of those alternatives (see Simon's view of decision making, 1976, as a classic example). Again, findings in this study do not appear consistent with this traditional rational view. Although alternatives and outcomes were coded in respondent interviews, neither seemed to play a dominant role in decision process. Frequencies of alternative codings were rather low compared to some other categories and wide ranges of considered alternatives were lacking. In some cases, alternatives were not considered at all. Aside from patterns such as the support or resistance of senior 
administration to change, expected and unexpected outcomes and constraints showed much less evidence of systematic pattern than was originally expected. Decision makers seemed to be, in part, consequentialists but in no apparent systemic way. Instead, perception of others, strategies, goals, and values seemed to dominate. This is somewhat consistent with another of Nutt's (1984) important findings. CEOs in his study were not seen to conform at all to normative decision making models found in the literature. Likewise, it cannot be inferred that respondents in this study follow normative decision models in any consistent way.

Aside from findings previously discussed, results of analysis of decision process in this study are in some ways disappointing. To the extent that this type of examination is an attempted analysis of the cognitive activity of respondents, the exact nature of the decision process continues to elude us. Although the decision process seems to unfold over some time frame, coding of categories and sub-categories was by no means strictly sequential. Findings here lend support to the notion that the essential nature of decision making cannot be captured in a linear model. Therefore, what has been described in terms of categories of decision process are, at best, some of the components of the decision making of respondents in this study.

A number of points are worth noting related to the analysis of values. First, values in this study were discerned as "part and parcel" of the decision process itself, although they are concepts which are seen as most fundamental to the decision process. In essence, values were answers to the question of why decisions were made. The coding of values in this study differed little from methods of coding for other categories, except perhaps for subsuming some concepts under others and identifying synonymy. No further interpretation of the content of values occurred. Thus, the study of values in this project is descriptive rather than prescriptive. No interest was taken in any meta-analysis of what value choices ought to have been made but rather what value choices were made.

Coding of values in both phases revealed some similarities and some differences. At least some degree of similarity appears to exist in the general frequency of occurrence of values across all cases in both 
phases. On the whole, some values such as fairness, shared decision making, institutional interests, students interests, and so on, which showed high occurrences in Phase I were also found to be highly occurring across case interviews in Phase II. When recurrences were compared by type, personnel cases in both phases clearly revealed fairness as dominant. The three highest recurring values in Phase II were among the top five in Phase I. In organizational redevelopment cases in Phase I, shared decision making recurred most frequently. In Phase II organizational redevelopment interviews, trust recurred most often, with shared decision making second. In addition, in Phase I, buildings and facilities cases showed few values, and two finance cases showed a surprisingly wide array of values including trust, shared decision making, shared vision, faimess, and honesty.

Finally, it appears as though respondents independently made some of the same value choices when reviewing the same set of problems. In Phase II, it was found that a number of values recurred exclusively in interviews on one case. For example, fairness recurred exclusively within the personnel case interviews, along with institutional interests, quality of education, and respect for persons. Shared decision making and shared vision also recurred exclusively within the organizational redevelopment case interviews. It is reasonably clear that respondents made some of the same value choices when confronted with the same problems. Furthermore, some recurrences identified in Phase II are consistent with findings within the same type in Phase I. In organizational redevelopment cases, values such as shared decision making and shared vision recurred again in Phase II organizational redevelopment interviews, and in personnel cases, fairness was most recurring overall in both phases. Given these findings there seems to be a fair extent of consistency, not only in Phase II, but also for value choices across phases within particular case types.

\section{Conclusion}

Many of the variables described in this study require further exploration within the larger framework of decision types or within other conceptual frameworks. Case attributes such as participation levels or decision 
strategies such as consultation, and most important, value choices, could be studied in relation to a host of other personal or contextual variables, and this must also include the application of designs specifically focused on such problems. Further, new thinking needs to be encouraged on the decision making process. New and creative approaches need to be devised to more clearly expose the nature of administrative decisions in higher education.

The fact that data analysis and interpretation depended almost solely on responses from one homogeneous professional group is a distinct limitation of this study. There is, no doubt, an obvious dichotomy between what respondents say they do and how other stakeholders in an organization perceive their actions. Designs such as the one described here point clearly to the need for additional study of conflicting perceptions of different stakeholders in organizations. The study of decisions and values of those who assume different roles in higher education institutions, how ethical problems are perceived, managed, and resolved, and how professional roles influence these factors, shows promise as a future area of inquiry. Findings for expected and unexpected outcomes in this study were, at best, sketchy. This same focus on multiple stakeholders may shed additional light on the consequences of ethical choice.

It could also be argued that the study of values in higher education has even greater implications. It was stated at the outset that values were assumed to underlie most important administrative decisions. If this is true, then it is inevitable that values and value conflicts permeate most if not all aspects of administrative practice in higher education. This means that most areas and issues in higher education including leadership, finance, program management, human resources, and planned change, and most administrative processes including policy, planning, implementation, and assessment, will be enriched through the study of values and understood more clearly from a values-oriented perspective. 


\section{References}

Ashbaugh, C., \& Kasten, K. (1984). A typology of operant values in school administration. Planning \& Changing, 15(4), 195-208.

Ashbaugh, C., \& Kasten, K. (1986). Administrative values and administrative action: A study of school superintendents. Planning \& Changing, 17(4), 239-251.

Baca, M., \& Stein, R. (Eds.). (1983). Ethical principles, practices, and problems in higher education. Springfield, IL: Charles C. Thomas.

Barnard, C. I. (1938). The functions of the executive. Cambridge, MA: Harvard University Press.

Beach, L. R., Mitchell, T. R., \& Drake, B. (1978). The effects of task conditions on subjective judgments. In B. King, S. Streufert, \& F. Fiedler (Eds.), Managerial control and organizational democracy (pp. 251-266). Washington, D.C.: V.H. Winston \& Sons.

Beck, C. M. (1991, June). A general approach to values. Unpublished manuscript, Ontario Institute for Studies in Education, Toronto, ON.

Begley, P. (1990). How administrators' values influence their decisions. Canadian School Executive, 10(4), 3-8.

Begley, P. T., \& Leithwood, K. A. (1990). The influence of values on school administrator practices. Journal of Personnel Evaluation in Education, 3(4), 337-352.

Bensimon, E., Neumann, A., \& Birnbaum, R. (1989). Making sense of administrative leadership: The "L" word in higher education. $A S H E-E R I C$ Higher Education Report No. 1. Washington, DC: School of Education and Human Development, The George Washington University.

Birnbaum, R. (1986). Leadership and learning: The college president as intuitive scientist. Review of Higher Education, 9, 381-395.

Birnbaum, R. (1987). Implicit leadership theories of college and university presidents. Paper presented at the annual meeting of the Association for the Study of Higher Education, Baltimore, MD.

Birnbaum, R. (1988). How colleges work: The cybernetics of academic organization and leadership. San Francisco: Jossey-Bass.

Birnbaum, R. (1992). How academic leadership works: Understanding success and failure in the college presidency. San Francisco: Jossey-Bass.

Bogdan, R. C., \& Biklen, S. K. (1992). Qualitative research for education: An introduction to theory and methods (2nd ed.). Boston, MA: Allyn and Bacon.

Borg, W. R., \& Gall, M. D. (1989). Educational research. New York, NY: Longman. 
Campbel1, C. E. (1992). Personal morals and organizational ethics: How teachers and principals cope with conflicting values in the context of school cultures. Unpublished doctoral dissertation, University of Toronto.

Campbell-Evans, G. H. (1991). Nature and influence of values in principal decision making. Alberta Journal of Educational Research, 37(2), 167-178.

Clark, B. (1982). Values. Los Angeles: Graduate School of Education, University of California.

Clark, B. (1983). Values in higher education: Conflict and accommodation. Tucson: Center for the Study of Higher Education.

Dennison, J. (1994). Values in the community college - Conflict and compromise. Unpublished manuscript.

Dennison, J., \& Gallagher, P. (1986). Canada's Community Colleges. Vancouver: University of British Columbia Press.

Dressel, P. (1981). Administrative leadership: Effective and responsive decision making in higher education. San Francisco: Jossey-Bass.

Evers, C. (1985). Hodgkinson on ethics and the philosophy of administration. Educational Administration Quarterly, 21(4), 27-50.

Evers, C. (1988). Educational administration and the new philosophy of science. Journal of Educational Administration, 26(1), 5-22.

Glasman, N., \& Sell, G. R. (1972). Values and facts in educational administrative decisions. Journal of Educational Administration, 10(2), 142-163.

Glendenning, D. (1980). Effective decision making. Journal of the Association of Canadian Community Colleges, 4(1-2), 117-122.

Greenfield, T. B. (1980). The man who comes back through the door in the wall: Discovering truth, discovering self, discovering organizations. Educational Administration Quarterly, 16(3), 26-59.

Greenfield, T. B. (1982). Against group mind: An anarchistic theory of organization. McGill Journal of Education, l7(1): 3-11.

Greenfield, T. B. (1986). The decline and fall of science in educational administration. Interchange, 17(2), 57-80.

Heller, F. (1973). Leadership, decision making, and contingency theory. Industrial Relations, 12(2), 183-199.

Heller, F., \& Yukl, G. (1969). Participation, managerial decision-making, and situational variables. Organizational Behavior and Human Performance, 4(3), 227-241.

Hodgkinson, C. (1978). Towards a philosophy of administration. Oxford: Basil Blackwell.

Hodgkinson, C. (1983). The philosophy of leadership. Oxford: Basil Blackwell. 
Hodgkinson, C. (1986). New directions for research and leadership: The triplex value bases of organizational theory and administration. Journal of Educational Administration and Foundations, l(1), 5-15.

Kasten, K., \& Ashbaugh, C. (Spring, 1988). A comparative study of values in administrative decision making. Journal of Research and Development in Education, 21(3), 16-23.

Kasten, K., \& Ashbaugh, C. (1991). The place of values in superintendents' work. Journal of Educational Administration, 29(3), 54-66.

Keast, D. A. (1994). Problems of validity in research on decision and values. Journal of Educational Administration and Foundations, 9(1), 9-25.

Kimbrough, R. B., \& Nunnery, M. Y. (1983). Educational administration: An introduction (2nd ed.). New York: MacMillan Publishing Company.

Kimbrough, R. B., \& Nunnery, M. Y. (1988). Educational administration: An introduction (3rd ed.). New York: Macmillan Publishing Company.

Krepel, T. (1990, October). Deciding to decide: Structuring decision situations and selecting decision strategies. Paper presented to the Midwest Council for Educational Administration, St. Cloud, Minnesota.

Lakomski, G. (1987). Values and decision making in educational administration. Educational Administration Quarterly, 23(3), 70-82.

LeCompte, M. D., \& Goetz, J. P. (1982). Problems of reliability and validity in ethnographic research. Review of Educational Research, 52(1), 31-60.

Leithwood, K. A., \& Stager, M. (1989). Expertise in principals' problem solving. Educational Administration Quarterly, 25(2), 126-161.

Leithwood, K. A., \& Steinbach, R. (1990). Characteristics of effective secondary school principals' problem solving. Journal of Educational Administration and Foundations, 5(1), 24-42.

May, W. W. (Ed.). (1990). Ethics and higher education. New York: MacMillan Publishing Co.

Miles, M. B., \& Huberman, A. M. (1984). Qualitative data analysis. Newberry Park, CA: Sage Publications

Mintzberg, H., Raisinghani, D., \& Theoret, A. (1976). The structure of "unstructured" decision processes. Administrative Science Quarterly, 21, 246-275.

Mintzberg, H., Waters, J., Pettigrew, A., \& Butler, R. (1990). Studying deciding: An exchange of views between Mintzberg and Waters, Pettigrew and Butler. Organization Studies, 11(1), 1-16.

Moorhead, R., \& Nediger, W. (1991). The impact of values on a principal's daily activities. Journal of Educational Administration, 29(2), 5-24. 
Nutt, P. (1984). Types of organizational decision processes. Administrative Science Quarterly, 29(3), 414-45

Plante, P. (1987). The art of decision making: Issues and cases in higher education. New York: MacMillan Publishing Co.

Raun, T., (1992, June). CEOs' values in problem solving. Paper presented at the annual conference of the Canadian Society for Studies in Education, Charlottetown, PE.

Robinson, G. M., \& Moulton, J. (1985). Ethical problems in higher education. Englewood Cliffs, NJ: Prentice-Hall, Inc.

Rokeach, M. (1973). The nature of human values. New York: Free Press.

Sandelowski, M. (1986). The problem of rigor in qualitative research. Advances in Nursing Science, 8(3), 27-37.

Simon, H. A. (1976). Administrative behavior (3rd ed.). New York: Free Press.

Smith, D. C. (1984). Program improvement through values audits. In D.Deshler (Ed.), Evaluation for program improvement. New Directions for Continuing Education, 24, 39-44.

Smith, D. C. (1985). Values and institutional decision making. Academe, 71(6), 14-18. Stewart, D. W. (1991). Theoretical foundations of ethics in public administration. Administration \& Society, 23(3), pp. 357-373.

Streufert, S. (1978). The human component in the decision-making situation. In B. King, S. Streufert, \& F. Fiedler (Eds.), Managerial control and organizational democracy (pp. 215-230). Washington, D.C.: V.H. Winston \& Sons.

Strike, K. A., Haller, E. J., \& Soltis, J. F. (1988). The ethics of school administration. New York and London: Teachers College Press.

Suedfeld, P. (1978). Characteristics of decision making as a function of the environment. In B. King, S. Streufert, \& F. Fiedler (Eds.), Managerial control and organizational democracy (pp. 203-214). Washington, D.C.: V.H. Winston \& Sons.

Thompson, D. L. (Ed.). (1991). Moral values and higher education. Albany, NY: State University of New York Press.

Vaughan, G. B. (1989). Leadership in transition: The community college presidency. New York: MacMillan Publishing Co.

Vaughan, G. B., \& Associates. (1992). Dilemmas of leadership: Decision making and ethics in the community college. San Francisco: Jossey-Bass.

Wilcox, J., \& Ebbs, S. (1992). The leadership compass: Values and ethics in higher education. ASHE-ERIC Higher Education Report No. 1. Washington, DC: School of Education and Human Development, The George Washington University. 